\begin{tabular}{|cc|}
\hline STOVE & COMBUSTION \\
FIRE & HAZARDS \\
BENZENE & BUTADIENE \\
ETHENE & ACETYLENE \\
SAMPLING & ANALYSIS \\
\hline
\end{tabular}

Open access manuscript version of Chemosphere 30 (1995) 1551-1556 doi:10.1016/0045-6535(95)00048-D

\title{
Volatile hydrocarbons from domestic wood burning
}

Gunnar Barrefors and Göran Petersson

\author{
Subsequent studies have focused on \\ phenolic antioxidants in wood smoke. \\ Comparable hydrocarbon assessments were made for \\ tobacco smoke and urban traffic emissions.
}




\title{
VOLATIE HYDROCARBONS FROM DOMESTIC WOOD BURNING
}

\author{
Gunnar Barrefors and Göran Petersson* \\ Department of Chemical Environmental Science \\ Chalmers University of Technology \\ 41296 Göteborg, Sweden
}

\begin{abstract}
The quantitative proportions of 16 alkenes, 5 alkadienes, 5 alkynes and several alkanes and arenes were determined in emissions from wood burning in a wood-stove and in small-scale model experiments. Samples were taken on triple-layer adsorption cartridges, and gas chromatographic separations were performed on an aluminium oxide column.

Ethene, ethyne and benzene were major components, especially from efficient flame combustion. The proportions of $\mathrm{C}_{3}-\mathrm{C}_{7}$ alkenes were markedly higher for smouldering. The carcinogenic compounds benzene and 1,3-butadiene constituted roughly $10-20 \%$ and $1-2 \%$ by weight of total non-methane hydrocarbons. Similar results were obtained for hardwood and softwood.
\end{abstract}

\section{INTRODUCTION}

Fuel wood is a major source of energy in homes in developing countries and has recently gained increased interest in many industrialized countries. An obvious environmental advantage is that wood may be a renewable and sustainable energy source without a net contribution to global warming from carbon dioxide. On the other hand, wood is increasingly questioned for small-scale home heating in Scandinavia and other regions because of large emissions to air due to inefficient combustion.

Semi-volatile air pollutants from wood burning have been characterized with respect to numerous polycyclic aromatic compounds (Freeman and Cattell, 1990 ; Hawthorne et al., 1992) and wood-specific phenolic compounds (Hawthorne et al., 1992 ; Hauk et al., 1994). Emissions of greenhouse gases, including methane and total non-methane organic compounds, have been studied for cookstoves in developing countries (Smith et al., 1993). Comprehensive studies including 
wood-related biomass and results for several specific hydrocarbons have been made using largescale laboratory burning (Sandberg et al., 1975 ; Lobert et al., 1991).

The purpose of the study at hand is to report the identities and proportions of a large number of volatile hydrocarbons emitted from incomplete wood burning. These hydrocarbons are of primary concern with regard to not only photooxidant formation (Atkinson, 1990) but also genotoxic health hazards (Törnqvist and Ehrenberg, 1994). The analytical methods are similar to and permit comparisons with previous studies of vehicle-emitted hydrocarbons in urban air (Barrefors and Petersson, 1993).

\section{EXPERIMENTAL}

\section{Wood burning}

The wood-stove for household cooking was made of iron with a built-in fireplace on a grid with variable air supply and a door for wood supply. The sampling point in the chimney exit on the roof was $\sim 6 \mathrm{~m}$ from the fireplace. Properly dried birchwood billets with bark were burnt. The related species Betula verrucosa and Betula pubescens are commonly used for domestic wood burning in Scandinavia.

The small-scale model burning was performed in a 11 ceramic pot which was covered with a larger pot to damp down the fire and to increase hydrocarbon concentrations when samples were taken. A hole in the bottom of the larger pot was used for sampling. The birchwood pieces were much smaller than those burnt in the stove. Chips of pine (Pinus sylvestris) were dried by indoor storing for six months before burning, thus removing most of the content of volatile monoterpenes.

\section{Analytical methods}

Previously reported methods for sampling and analysis of hydrocarbons in air (Barrefors and Petersson, 1993) were somewhat modified to suit studies of wood burning. The same triple-layer adsorption cartridges (Tenax TA + Carbotrap + Carbosieve S-III) were used for sampling. Sampling volumes as small as $\sim 10 \mathrm{ml}$ prevented losses by break-through and chemical decomposition in the cartridges. Complementary samples on Tenax cartridges served as a further check of recovery of reactive hydrocarbons. Chimney samples (1-5 min) were taken in the summer season during initial flaming fire and, after $\sim 20 \mathrm{~min}$, during smouldering.

In the laboratory, the pollutants were desorbed at $235^{\circ} \mathrm{C}\left(\mathrm{He}\right.$ ) into a cold (liquid $\mathrm{N}_{2}$ ) trap consisting of an empty column (FSOT, $5 \mathrm{~m} \times 0.32 \mathrm{~mm}$ i.d.). Heating of the column coil in an oil bath injected the hydrocarbons onto the analytical $\mathrm{Al}_{2} \mathrm{O}_{3} / 5 \% \mathrm{KCl}$ column (PLOT, $50 \mathrm{~m} \times 0.32 \mathrm{~mm}$ i.d. fused silica, Chrompack) of the gas chromatograph. The analytical temperature and time sequence (following injection after desorption for $14 \mathrm{~min})$ was $30-110^{\circ} \mathrm{C}\left(10^{\circ} \mathrm{C} \mathrm{min}-1\right), 110^{\circ} \mathrm{C}(14$ $\min ), 110-200^{\circ} \mathrm{C}\left(4^{\circ} \mathrm{C} \mathrm{min}^{-1}\right)$ and $200^{\circ} \mathrm{C}$ (as long as required). Gaseous samples were transferred into and injected from an empty column coil $(3.2 \mathrm{ml})$ which bypassed the desorption oven in the carrier gas line. The response of the flame ionization detector was set equal for all hydrocarbons when calculating quantitative proportions.

Mass spectrometric identifications of the hydrocarbons were made on a Varian Saturn II ion trap GC-MS system. Comparisons with reference GC retention data were used to confirm the identities. 
Gaseous samples were taken with a gas-tight syringe $(50 \mathrm{ml})$. Carbon dioxide was determined on a gas chromatograph equipped with gas injection valves, a porous polymer column (HayeSep Q, $\left.190 \mathrm{~cm} \times 1 / 8^{\prime \prime}\right)$ and a thermal conductivity detector $\left(150 \mathrm{~mA}, 200^{\circ} \mathrm{C}\right)$. The carrier gas was helium and the column temperature $80^{\circ} \mathrm{C}$.

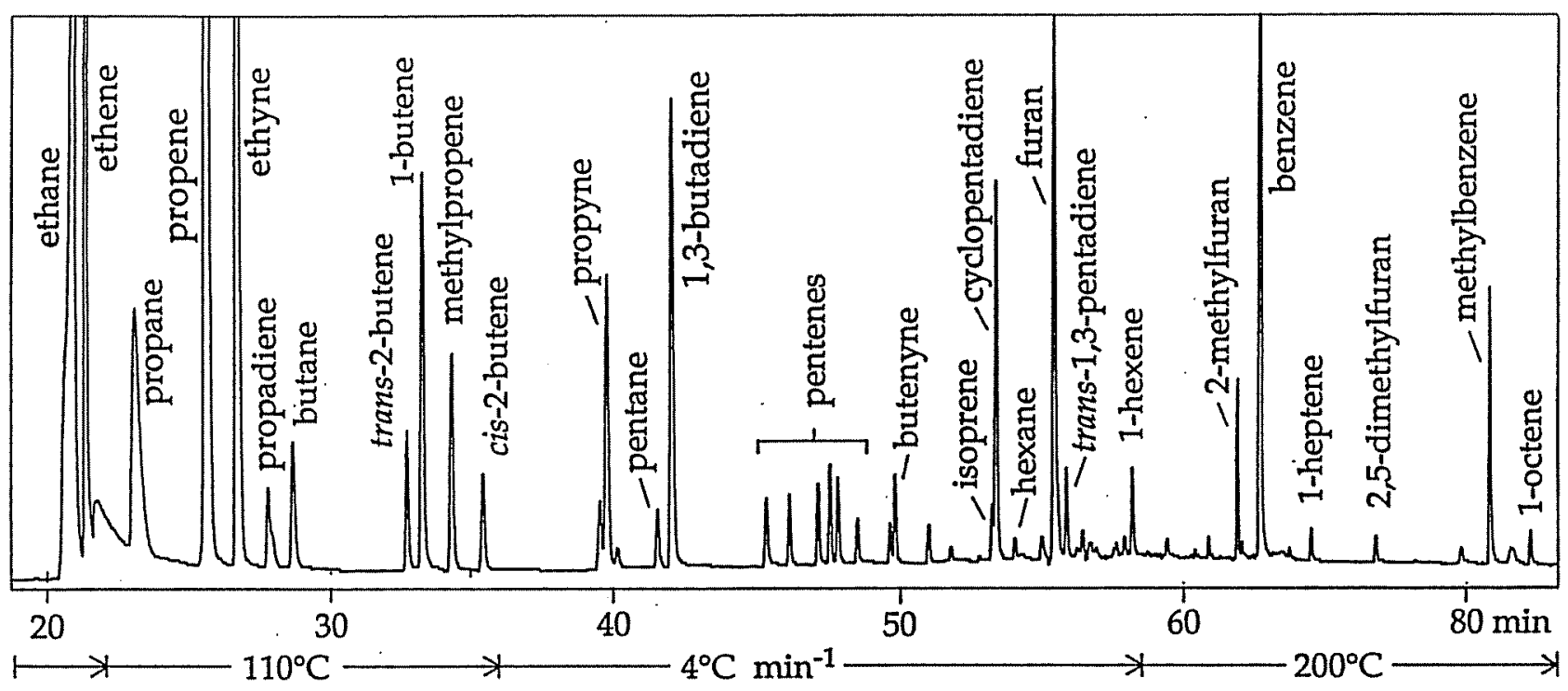

Figure 1. Gas chromatographic separation of chimney-sampled hydrocarbons from glowing birchwood remainders in a wood-stove (aluminium oxide column; flame ionization detector; decreased paper speed from 60 and $80 \mathrm{~min}$ ).

\section{RESULTS}

The chromatogram in Fig. 1 illustrates the separation of the prominent volatile hydrocarbons from wood burning. The range of combustion-formed hydrocarbons conforms with the most favourable working range of the aluminium oxide column.

The most representative quantitative results of the study are given in Table 1 as hydrocarbon proportions. The hydrocarbons are arranged according to structural class, number of carbon atoms, and retention on the $\mathrm{Al}_{2} \mathrm{O}_{3}$ column. The first two columns give results for chimney-sampled emissions from hardwood burning in a wood-stove. The proportions of the major hydrocarbons ethene, ethyne and benzene are higher from the flaming fire than from the subsequent smouldering combustion. The reverse is true for $\mathrm{C}_{3}-\mathrm{C}_{8}$ alkenes and alkadienes as well as for alkanes.

The results given in the $3 \mathrm{rd}$ and 4 th columns illustrate hydrocarbon proportions from smallscale wood burning which is more inefficient than wood-stove burning. The almost identical results for gas syringe sampling and adsorption sampling confirm that no significant losses occur neither by chemical decomposition of reactive hydrocarbons nor by break-through on the triple-layer adsorption cartridges. The results in the last column for the burning of dry pine chips demonstrate that hydrocarbons are emitted in surprisingly similar proportions from hardwood and softwood.

As seen from Fig. 1, furan and 2-methylfuran are prominent products from wood combustion. Oxygen-containing compounds are retained irreversibly by the $\mathrm{Al}_{2} \mathrm{O}_{3}$ column with the exception of the furans, characterized by a stable aromatic structure. Compared to benzene, the proportion of 
Table 1. Composition (\% weight) of $\mathrm{C}_{2}-\mathrm{C}_{8}$ hydrocarbons from wood burning.

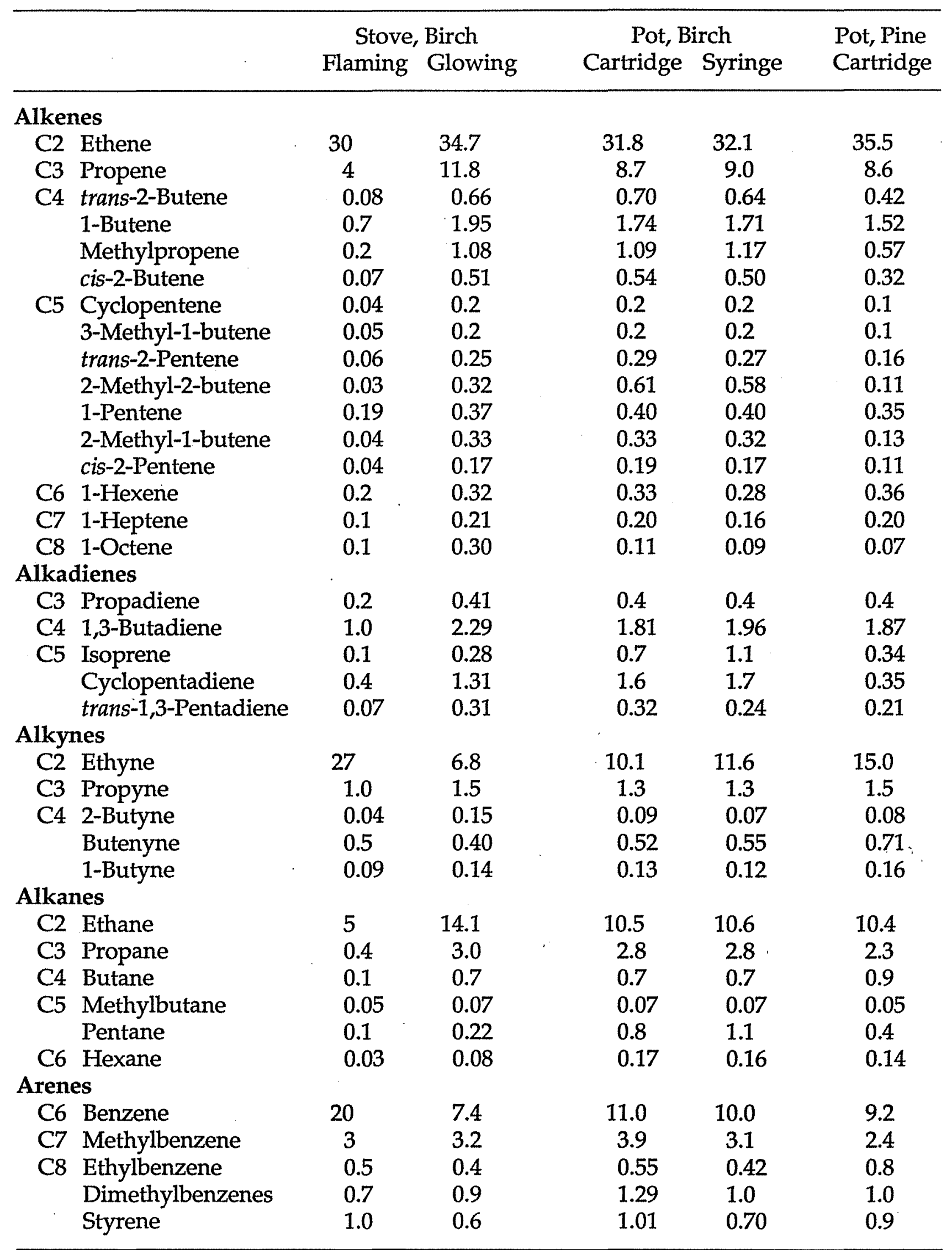

The total concentrations for the five samples were $13,19,630,300$, and $45 \mathrm{mg} \mathrm{m}^{-3}$. The concentrations of carbon dioxide were 55 and $27 \mathrm{~g} \mathrm{~m}^{-3}$ for the flaming stove fire and the pot burning of birchwood. The chromatogram of the stove sample for glowing birchwood is given in Fig.1. 
furan was found to be considerably larger for pot-burning of dry birchwood but much smaller for the more efficient burning in the wood-stove.

\section{DISCUSSION}

\section{Wood burning}

The results indicate that the hydrocarbon proportions depend more on the character of the combustion than on the plant species and chemical character of the wood. The basic changes in relative proportions on a scale from inefficient smouldering to efficient flaming combustion are indicated in Fig. 2 for hydrocarbons of particular interest. The diagram is based on several complementary burning experiments in addition to those reported. The proportion of ethyne increases sharply with increasing combustion efficiency whereas the proportions of butenes and higher alkenes decrease markedly. Benzene, ethene, 1,3-butadiene and propene are intermediate in this order. Ethyne, ethene and benzene were found to make up well over $80 \%$ of the non-methane hydrocarbons for efficient flame combustion of wood. The proportions for low-temperature smouldering are similar to those of environmental tobacco smoke (Barrefors and Petersson, 1993).

Differences between flaming and smouldering combustion, consistent with those illustrated in Fig.2, have been reported for controlled biomass burning in large experimental devices (Sandberg et al., 1975 ; Lobert et al., 1991). These studies also clearly demonstrated that the hydrocarbon and carbon monoxide emissions relative to fuel loss and carbon dioxide formation are much larger for smouldering than for flaming combustion. The total hydrocarbon to carbon dioxide concentration ratios given below Table 1 differ accordingly between the flaming stove fire and the partly smouldering pot-burning of birchwood. The ratios observed for cookstoves without chimney in south-east Asia (Smith et al., 1993) were intermediate, indicating a wide validity of the tabulated hydrocarbon proportions.

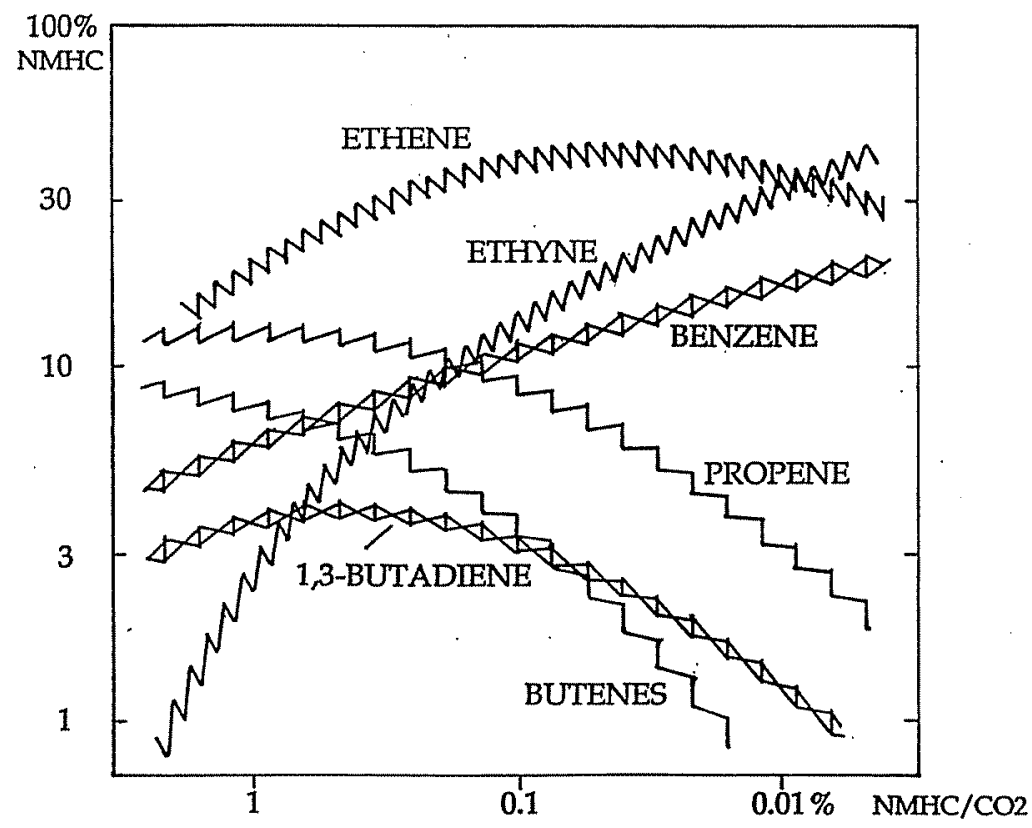

Figure 2. Approximate percent proportions of prominent specific hydrocarbons relative to total non-methane hydrocarbons (NMHC) from biomass burning. The decrease in hydrocarbon to carbon dioxide ratio from 1 to $0.01 \%$ reflects a shift from smouldering to flaming combustion. 


\section{Environmental pollution}

The proportions, environmental impact, and health hazards of hydrocarbons from wood burning may be discussed with reference to the extensively studied vehicle-emitted hydrocarbons (Barrefors and Petersson, 1993). The hydrocarbons from wood burning differ from those in traffic-polluted urban air by higher proportions of ethene and alkadienes and lower proportions of alkanes and alkylbenzenes which are emitted as unburnt petrol components. Ethyne may be a suitable tracer hydrocarbon for emissions from efficient wood-burning installations.

The high proportions of alkenes and low proportions of alkanes should make emissions from small-scale and uncontrolled wood burning more reactive in photooxidant formation (Atkinson, 1990) than equally large traffic emissions. Wood burning for home heating occurs only to a little extent in the warm photooxidant season, however.

The high proportions of the genotoxic hydrocarbons ethene, propene, 1,3-butadiene and benzene are of concern with respect to health hazards (Törnqvist and Ehrenberg, 1994). It should be remembered however, that chimney emissions give rise to much lower human exposure than equally large ground-level vehicle emissions.

\section{REFERENCES}

Atkinson R. (1990). Gas-phase tropospheric chemistry of organic compounds: A review. Atmos. Environ. 24A, 1-41.

Barrefors G. and Petersson G. (1993). Assessment of ambient volatile hydrocarbon from tobacco smoke and from vehicle emissions. J. Chromatogr. 643, 71-76.

Freeman D. J. and Catell F. C. R. (1990). Woodburning as a source of atmospheric polycyclic aromatic hydrocarbons. Environ. Sci. Technol. 24, 1581-1585.

Hauk A., Sklorz M., Bergmann G. and Hutzinger O. (1994). Analysis and toxicity testing of combustion gases. I. A new sampling unit for collection of combustion products. J. Anal. Appl. Pyrolysis 28, 1-12.

Hawthorne S. B., Miller D. J., Langenfeld J. J. and Krieger M. S. (1992). PM 10 High-volume collection and quantitation of semi- and nonvolatile phenols, methoxylated phenols, alkanes, and polycyclic aromatic hydrocarbons from winter urban air and their relationship to wood smoke emissions. Environ. Sci. Technol. 26, 2251-2262.

Lobert J. M., Scharffe D. H., Hao W.-M., Kuhlbusch A., Seuwen R., Warneck P. and Crutzen P. J. (1991). In Proceedings of the 1990 Chapman conference on global biomass burning, ed. J. S. Levine, MIT Press, Cambridge, pp 289-304.

Sandberg D. V., Pickford S. G. and Darley E. F. (1975). Emissions from slash burning and the influence of flame retardant chemicals. JAPCA 25, 278-281.

Smith K. R., Khalil M. A. K., Rasmusen R. A., Thorneloe S. A., Manegdeg F. and Apte M. (1993). Greenhouse gases from biomass and fossil fuel stoves in developing countries; a Manila pilot study. Chemosphere 26, 479-505.

Törnqvist M. and Ehrenberg L. (1994). Cancer risk: Estimation of urban air pollution. Environ. Health Perspect. 102 (Suppl. 4), 173-182. 